\title{
MUSEUM SENI RUPA MODERN DI PONTIANAK
}

\author{
Rahma Aulia $^{1}$, Zairin Zain ${ }^{2}$, Valentinus Pebriano ${ }^{3}$ \\ ${ }^{1}$ Mahasiswa, Program Studi Arsitektur, Fakultas Teknik, Universitas Tanjungpura. \\ Rahmaaulia07@student.untan.ac.id \\ ${ }^{2}$ Program Studi Arsitektur, Fakultas Teknik, Universitas Tanjungpura \\ ${ }^{3}$ Program Studi Arsitektur, Fakultas Teknik, Universitas Tanjungpura
}

Naskah diajukan pada: 19 Februari 2021

Naskah revisi akhir diterima pada: 21 Februari 2021

\begin{abstract}
Abstrak
Museum secara umum untuk menyimpan, merawat, mengamankan dan memanfaatkan koleksi museum berupa benda cagar budaya. Museum seni rupa diapresiasi melalui penglihatan dengan media yang tampak dan memiliki wujud fisik atau hanya disajikan sebagai pertunjukan. Kota Pontianak belum mempunyai wadah untuk menjalani fungsi museum seni rupa tersebut. Koleksi museum berfokus pada seni rupa modern dengan pinjaman jangka panjang pada museum. Terdapat beberapa peminat seni di Pontianak tetapi tidak ada wadah untuk menyalurkan minat tersebut. Metode perancangan menggunakan tiga tahapan. Tahap pertama, pengambilan data dengan mengklasifikasikan data sebagai keterangan dan fakta pada suatu persoalan. Tahap kedua, analisis bertujuan untuk menganalisa data yang telah didapatkan. Tahap ketiga, sistematika dan sistematis dengan menggunakan gambar berupa tahap dengan hasil produk yaitu, gambar rencana dan laporan perancangan. Perancangan Museum Seni Rupa Modern di Pontianak menggunakan pendekatan arsitektur hijau, yakni perencanaan bangunan yang berusaha meminimalisasi berbagai pengaruh membahayakan pada kesehatan manusia dan lingkungan. Museum ini mempunyai dua lantai dibagi sesuai fungsi yaitu fungsi pengelola dan pengunjung. Fasad yang diguanakan adalah jenis 3R (Reduce, Reuse, Recycle), sehingga dinding menggunakan batu bata dan pada jendela akan menggunakan material low e-glass dan kusen uPVC. Adapun komposisi pembanding 60:40 untuk bangunan dan lahan hijau mengikuti persyaratan pembangunan museum.
\end{abstract}

Kata-kata kunci: museum, seni, seni rupa modern, dan arsitektur hijau

\begin{abstract}
Museums in general are used to store, maintain, secure and utilize museum collections in the form of cultural heritage objects. Fine arts museums are appreciated through visions with visible media and have a physical form or simply presented as a show. The city of Pontianak does not yet have a place to carry out the function of this fine art museum. The museum collection focuses on modern fine art with long-term loans to the museum. There are some art enthusiasts in Pontianak but there is no place to channel this interest. The design method uses three stages. The first stage, data collection by classifying data as information and facts on a problem. The second stage, the analysis aims to analyze the data that has been obtained. The third stage is systematic and systematic by using images in the form of stages with product results, namely, planning drawings and design reports. The design of the Modern Art Museum in Pontianak uses a green architectural approach, namely building planning that seeks to minimize various harmful influences on human health and the environment. This museum has two floors divided according to functions, namely manager and visitor functions. The facade used is of the 3R type (Reduce, Reuse, Recycle), so the walls use bricks and the windows will use low e-glass material and uPVC frames. The comparison composition of 60:40 for buildings and green land follows the requirements for building a museum.
\end{abstract}

Keywords: museum, art, modern fine arts, and green architecture 


\section{Pendahuluan}

Berdasarkan Direktorat Museum Departemen Kebudayaan dan Pariwisata tahun 2007, museum merupakan suatu badan tetap, tidak tergantung siapa pemiliknya. Museum merupakan tempat kesenangan, tetapi juga untuk kepentingan studi dan penelitian. Museum terbuka untuk umum. Kehadiran fungsi-fungsi museum untuk kepentingan dan kemajuan masyarakat.

Seni rupa modern didefinisikan sebagai seni rupa diciptakan dengan ide dan wujud yang tidak terbatas pada budaya atau pakem-pakem suatu daerah. Seni rupa modern adalah hasil karya seni rupa yang tercipta dari kreativitas dan inovasi. Karya-karya dalam seni rupa modern menekankan beberapa unsur antara lain unsur eksperimen, pembaruan, kebaruan, dan orisinalitas. Karya yang dihasilkan seni rupa modern berupa kerajinan keramik, patung, lukisan, kaligrafi, furniture, dan mosaik. Pengembangan seni rupa modern berdasarkan filsafat, ilmu dan prinsip-prinsip seni yang lebih maju. Istilah modern dalam seni rupa dikaitkan dengan seni dimana tradisi masa lalu telah dikesampingkan dalam rangka mengangkat eksperimen demi kemajuan seni. Koleksi museum difokuskan pada seni rupa modern dari Kalimantan Barat, diambil dari koleksi seniman lokal, dan dengan pinjaman jangka panjang ke museum.

Pontianak mempunyai suhu rata-rata 28,1-30,1 derajat celcius. Kelembaban udara antara 99,58\% dan 48,83\%. Lama penyinaran sinar matahari antara 53\% dan 73\%. Untuk meminimalkan perolehan panas matahari, maka menggunakan pendekatan arsitektur hijau, yakni suatu pendekatan perancangan bangunan yang berusaha meminimalisir berbagai pengaruh membahayakan kesehatan manusia dan lingkungan. Arsitektur hijau ini diaplikasikan pada rancangan di kawasan tropis lembab. Pontianak belum memiliki museum seni, terdapat beberapa peminat seni di Pontianak dan sekitarnya tetapi tidak ada wadah untuk menyalurkan minat. Apabila terdapat wadah yang tersedia maka akan menumbuhkan yang tadinya tidak tahu dan minat terhadap seni khususnya seni rupa akan ada rasa keingintahuan akan hal yang dapat dilihat.

Pada permasalahan yang telah diuraikan guna mengangkat nama-nama tokoh seniman lokal dan edukasi pada peminat seni di Pontianak. Perancangan seni rupa modern dirancang dengan menggunakan pendekatan arsitektur hijau pada gedung, maka museum seni rupa modern ini memiliki manfaat bagi masyarakat Pontianak.

\section{Kajian Pustaka}

Menurut Direktorat Museum Departemen Kebudayaan dan Pariwisata tahun 2007, museum merupakan suatu badan tetap, tidak tergantung kepada siapa pemiliknya melainkan harus tetap ada. Museum bukan hanya merupakan tempat kesenangan, tetapi juga untuk kepentingan studi dan penelitian. Museum terbuka untuk umum dan kehadiran serta fungsi-fungsi museum adalah untuk kepentingan dan kemajuan masyarakat. Berdasarkan Undang-Undang Nomor 19 tahun 1995, mendefenisikan museum sebagai lembaga, tempat penyimpanan, perawatan, pengamanan dan pemanfaatan.

Kebutuhan ruang museum meliputi, ruang pameran, pameran yang tetap dan temporer, ruang untuk penyimpanan karya-karya, ruang untuk belajar, dan ruang untuk rapat. Fungsi ruang rekreasi meliputi ruang ruang santai, kafe, dan restoran. Adapun ruang servis, meliputi tempat penyimpanan barang, ruang pengawetan, depot, bengkel, organisasi, dan administrasi (Neufert, 2002).

Jenis museum ada bermacam-macam dan dapat ditinjau dari berbagai sudut, yang paling sering digunakan adalah koleksinya. Selain itu jenis museum juga dapat ditinjau dari segi penyelenggara dan kedudukannya (Susilo, 1993).

Definisi museum rumusan ICOM, mengemukakan sembilan fungsi museum sebagai berikut: pengumpulan dan pengamanan warisan alam dan budaya, dokumentasi dan penelitian ilmiah, konservasi, penyebaran dan pemerataan ilmu untuk umum, pengenalan dan penghayatan kesenian, pengenalan kebudayaan antar-daerah dan antar-bangsa, visualisasi warisan alam dan budaya, cermin 
pertumbuhan peradaban umat manusia, dan pembangkit rasa bertakwa dan bersyukur kepada Tuhan Yang Maha Esa (Sutaarga, 1989).

Menurut Pamiji tahun 2010, Museum memiliki beberapa fungsi yaitu, museum untuk memenuhi tujuan penelitian, pendidikan, dan hiburan. Fungsi primer sebagai tempat menyimpan, merawat, mengamankan, dan memanfaatkan koleksi berupa cagar budaya. Fungsi sekunder sebagai sarana edukasi program pendidikan menyediakan akses seni, dalam kaitan dengan pameran yang dilihat, melalui pameran dan seminar yang menarik. Fungsi pendukung sebagai sarana hiburan dan rekreasi terdapat toko souvenir dan kafetaria.

Seni adalah karya cipta manusia yang diwujudkan pada media dan dapat dinikmati keindahannya, yang tidak meninggalkan prinsip dan unsur atau kaidah-kaidah berkesenian, dengan tujuan untuk mencapai kepuasan lahir maupun batin. Seperti dijelaskan Sachari (2001) bahwa seni (art) adalah hal-hal yang diciptakan dan diwujudkan oleh manusia, yang dapat memberi rasa kesenangan dan kepuasan dengan pencapaian rasa indah. Seni dibagi kedalam tiga kelompok besar, yaitu seni penglihatan, seni pendengaran, dan seni penglihatan pendengaran. Seni dikelompokkan menjadi, (visual arts) seni penglihatan, (auditory arts) seni pendengaran, dan (visual-auditory arts) seni penglihatan pendengaran (Sumardjo, 2000).

Menurut Direktorat Musem Departemen Kebudayaan dan Pariwisata tahun 2008, museum seni, lebih dikenal dengan nama galeri seni, merupakan sebuah ruangan untuk pameran benda seni, mulai dari seni visual yaitu diantaranya lukisan, gambar, dan patung. Beberapa contoh lainnya seni keramik, seni logam, mosaik dan furnitur. Museum yang memberikan sebuah ruang untuk pameran seni, merupakan seni visual, terdiri dari lukisan, ilustrasi, dan patung. Koleksi dari lukisan dan dokumen lama biasanya tidak dipamerkan di dinding, akan tetapi diletakkan di ruangan khusus.

Menurut periodisasi seni rupa modern adalah istilah yang digunakan untuk mengkategorisasikan berbagai karya seni rupa yang dihasilkan pada tahun 1860-an hingga 1970-an. Sifat dan ciri seni rupa modern yaitu, eksperimental, pembaruan (innovation), mengusung nilai baru (novelty), dan orisinal. Adapun ciri-ciri seni rupa modern yaitu, tidak terikat pada pakem-pakem tradisi atau budaya penjabaran visualnya lebih ekspresif dan bebas, namun tetap berbasis pada berbagai penemuan filsafat, prinsip-prinsip dan ilmu yang baru, universal, tidak terpaku pada satu aliran dan tidak memiliki kepentingan lembaga diluar seni itu sendiri. Berlandaskan seni untuk kepentingan seni itu sendiri makabentuk geometris (pengaruh ilmu geometri) menjadi dominan. Aliran seni rupa modern lainnya terus bermunculan dan berkembang setelah pergerakan para impressionist, diantaranya saling berdialog satu sama lain. Terdapat aliran seni rupa modern barat yang saling mengembangkan, juga saling bertentangan (Atkins, 1990).

Arsitektur hijau merupakan suatu pendekatan perencanaan bangunan yang berusaha untuk meminimalisasi berbagai pengaruh membahayakan kesehatan manusia dan lingkungan. Rancangan arsitektur hijau yang baik, menerapkan sistem hemat energi yang membuat lingkungan sekitar menjadi lebih baik. Untuk bisa mendapatkannya maka area sekitar harus memenuhi kriteria rancangan arsitektur hijau. Adapun syarat yang harus dipenuhi untuk mencapai kriteria rancangan. Penempatan lokasi yang terhindar dari bahaya bagi pengguna. Pengolahan tapak dan peningkatan kualitas tapak pada saat merancang bangunan disarankan tidak terlalu megubah area tapak karena dapat mengganggu kualitas tanah. Penghematan energi mampu membuat bangunan meminimalkan penggunaan energi buatan, dan membuat bangunan memanfaatkan sumber daya alam sekitarnya meliputi, meminimalkan radiasi matahari secara langsung, menghindari arah hadap bangunan ke matahari langsung, memaksimalkan sirkulasi udara pada bangunan, memanfaatkan sinar matahari yang tidak terkena kebangunan sebagai penerangan, desain luar bangunan, penggunaan warna dan tekstur luar bangunan. Pemanfaatan energi terbarukan sangat ramah terhadap lingkungan yang mana penggunaannya bisa secara terus menerus sehingga membantu mengemisi $\mathrm{CO}_{2}$ dan efek gas rumah kaca. Adapun energi terbarukan tersebut antara lain energi surya, energi angin, energi air, energi panas bumi (Karyono, 2014). 


\section{Metode}

Metode perancangan menggunakan tiga tahapan. Tahap pertama, pengambilan data dengan mengklasifikasikan data sebagai keterangan dan fakta pada suatu persoalan untuk dianalisis dan dicari solusinya. Adapun data yang diambil yaitu, data primer, data sekunder data yang dikumpulkan langsung dari sumber pertama. Cara mendapatkan data primer melalui survei dan wawancara. Selanjutnya data sekunder dalam bentuk dokumen atau literatur dari instansi terkait. Tahap kedua, analisis bertujuan untuk menganalisa data yang telah didapatkan, tahap analisis bertujuan untuk analisis fungsi, kegiatan, program, lokasi, pelaku kegiatan, susunan ruang, utilitas, dan bentuk. Tahap ketiga, sistematika rancangan menggunakan gambar berupa, gambar rencana, gambar susunan bangunan, dan laporan perancangan.

\section{Hasil dan Pembahasan}

Lokasi bangunan Museum Seni Rupa Modern terletak di Jalan Jenderal Ahmad Yani, Kecamatan Pontianak Tenggara dengan luas lahan $15.884 \mathrm{~m}^{2}$. Jaringan jalan site termasuk jaringan jalan primer, dengan KDB $40 \%$, KLB 4, KDH $60 \%$, GSB 9 meter.

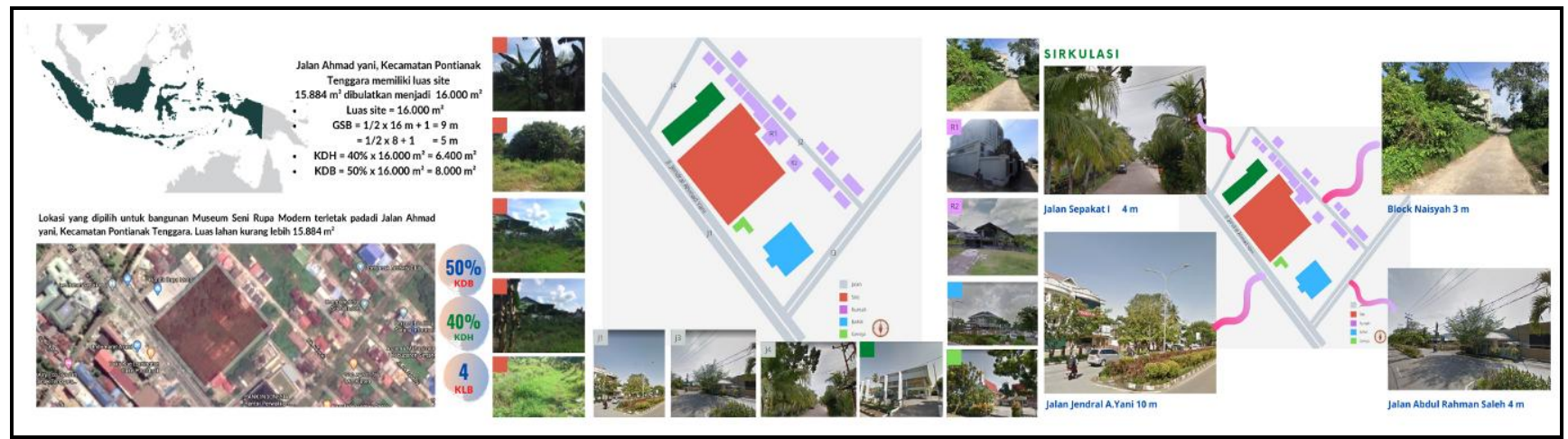

Gambar 1. Lokasi Perancangan Museum Seni Rupa Modern di Pontianak

Sumber: Penulis, 2020

Perancangan Museum Seni Rupa Modern di Pontianak menggunakan pendekatan arsitektur hijau perencanaan bangunan yang berusaha untuk meminimalisasi berbagai pengaruh membahayakan kesehatan manusia dan lingkungan. Adapun komposisi pembanding 60:40 untuk bagunan dan lahan hijau dan mengikuti persyaratan ruang pembangunan museum. Fasad dan kaca menggunakan 3R (reduce, reuse, recycle), sehingga dinding akan menggunakan batu bata dan pada jendela akan menggunakan material low e-glass dan kusen $u P V C$.

Pelaku pada museum mengacu Undang-Undang Nomor 66 Tahun 2015, sumber daya manusia paling sedikit terdiri atas kepala museum, tenaga teknis, dan tenaga administrasi. Analisis pelaku Museum Seni Rupa Modern di Pontianak menyesuaikan dengan fungsi museum, persyaratan umum museum, dan tinjauan museum seni rupa. Adapun pelaku utama pada Museum Seni Rupa Modern ini yaitu pengunjung, untuk pengelola terdiri dari. kepala museum, pengelola kurator, tenaga konservasi, tenaga administrasi, tenaga edukasi, staf operator, dan teknisi servis.

Kebutuhan ruang pada museum mempunyai jumlah besaran ruang 10,038 $\mathrm{m}^{2}$ dengan sirkulasi $20 \%$ sampai $40 \%$, meliputi ruang lobby pengelola, drop off, teras, ruang tamu, ruang kepala museum, ruang staf museum, ruang rapat, ruang kepala staf, ruang kepala administrasi, ruang mekanikal, ruang operator, ruang penyimpanan lukisan, ruang penyimpanan patung, ruang penyimpanan keramik, ruang penyimpanan furniture, ruang laboratorium restorasi, ruang staf kurator, ruang pameran temporer, dapur pengelola, kafetaria, gudang alat, lavatory, dan musholla, ruang pameran tetap, ruang seminar, ruang workshop ruang pameran khusus. 
Analisis perancangan terbagi menjadi lima meliputi, analisis peletakan, analisis orientasi, analisis sirkulasi, analisis vegetasi, dan analisis zonasi. Analisis peletakan bangunan pada tengah site, menghadap ke jalan utama (Jalan Jenderal Ahmad Yani). Bangunan diletakkan pada tengah site agar tidak terlalu bising. Analisis orientasi menghasilkan arah bangunan menghadap ke jalan utama (Jalan Jenderal Ahmad Yani) menjadi entrance utama dan dan membelakangi Blok Naisyah yang akan menjadi secound entrance.

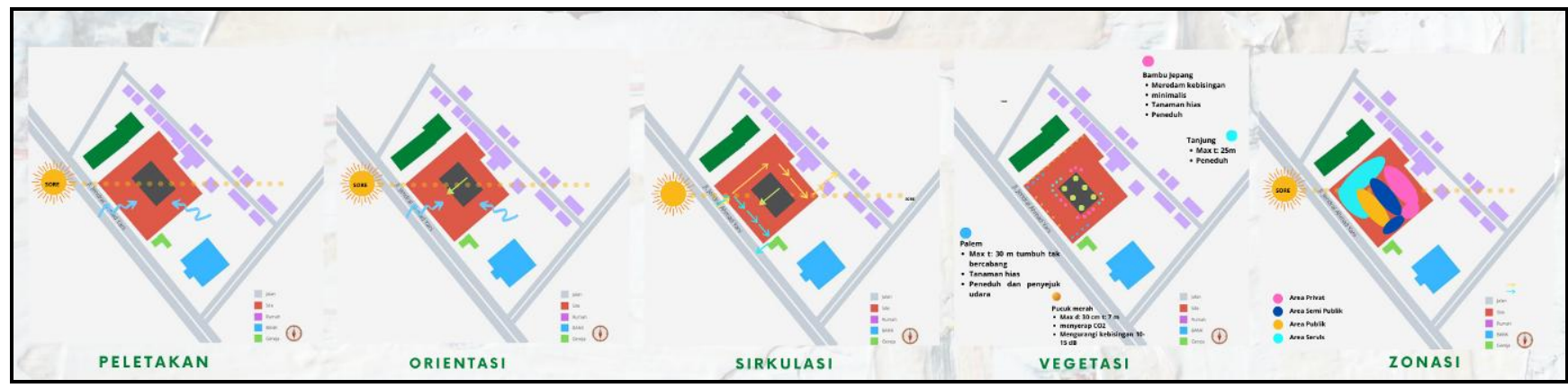

Gambar 2. Hasil Analisis

Sumber: Penulis, 2020

Analisis sirkulasi menghasilkan pola sirkulasi untuk mempengaruhi keteraturan lalu lintas dan kenyamanan menuju site. Bagian depan digunakan untuk lahan parkir pengunjung arah Jalan Jenderal Ahmad Ayani. Bagian samping kiri site digunakan untuk parkir bus, parkir motor pengunjung, parkir motor pengelola, dan taman. Bagian belakang digunakan untuk parkir truk pengelola dan entrance kedua khusus keluar masuk barang museum.

Analisis vegetasi menghasilkan lima tanaman pada site museum yaitu pertama, tanaman tanjung yang mempunyai tinggi maksimal $25 \mathrm{~m}$ berfungsi sebagai peneduh. Kedua, bambu jepang yang berbentuk minimalis serta berfungsi sebagai peredam kebisingan, tanaman hias dan peneduh. Ketiga, pucuk merah memiliki tinggi maksimal $7 \mathrm{~m}$, serta berfungsi untuk menyerap $\mathrm{CO} 2$ dan mengurangi kebisingan 10-15 dB. Keempat, palem memiliki tinggi maksimal $30 \mathrm{~m}$, merupakan tumbuhan yang tumbuh tak bercabang serta memiliki fungsi sebagai tanaman hias, peneduh dan penyejuk udara. Jenis tanaman kelima ditanami pada bagian atap dengan rumput.

Analisis zonasi meliputi, area semi publik, area privat, area publik dan area servis. Area semi publik diletakkan antara area publik dan area privat supaya melindungi akses ke area privat. Area privat berada di arah timur site dan bersebelahan dengan area kosong serta kebisingan rata-rata dan bagian center sebagai area publik karena untuk entrance dan pameran. Arah barat baiknya menjadi area parkir dan servis, bagian center sebagai area publik karna untuk entrance dan pameran, area semi publik diletakkan diantara area publik dan area privat supaya melindungi akses ke area privat, area privat berada di arah timur site.

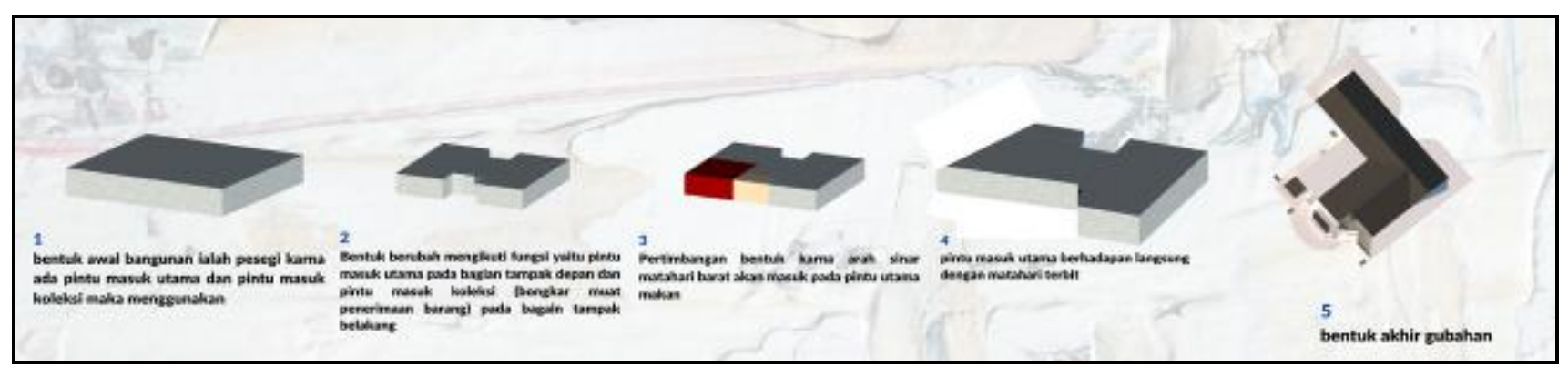

Gambar 3. Analisis Bentuk

Sumber: Penulis, 2020 
Gubahan bentuk terdiri dari pengaplikasian atap bangunan, fasad, warna, maupun material yang digunakan pada eksterior bangunan. Bentuk awal bangunan berbentuk kubus mengikuti aliran seni rupa modern kubisme dengan berbagai pengurangan massa dengan mempertimbangkan pencahayaan dan entrance gedung. Bentuk kubus mengalami pengurangan massa dan pertimbangan arah sinar matahari mewujudkan hasil bentuk akhir. Penambahan massa terjadi pada bentuk atap segitiga karena menggunakan pendekatan arsitektur hijau. Bentuk bangunan mengikuti konsep dari hasil analisis preseden meliputi, penempatan fungsi ruang, material, penggunaan fasad dan bentuk bangunan.

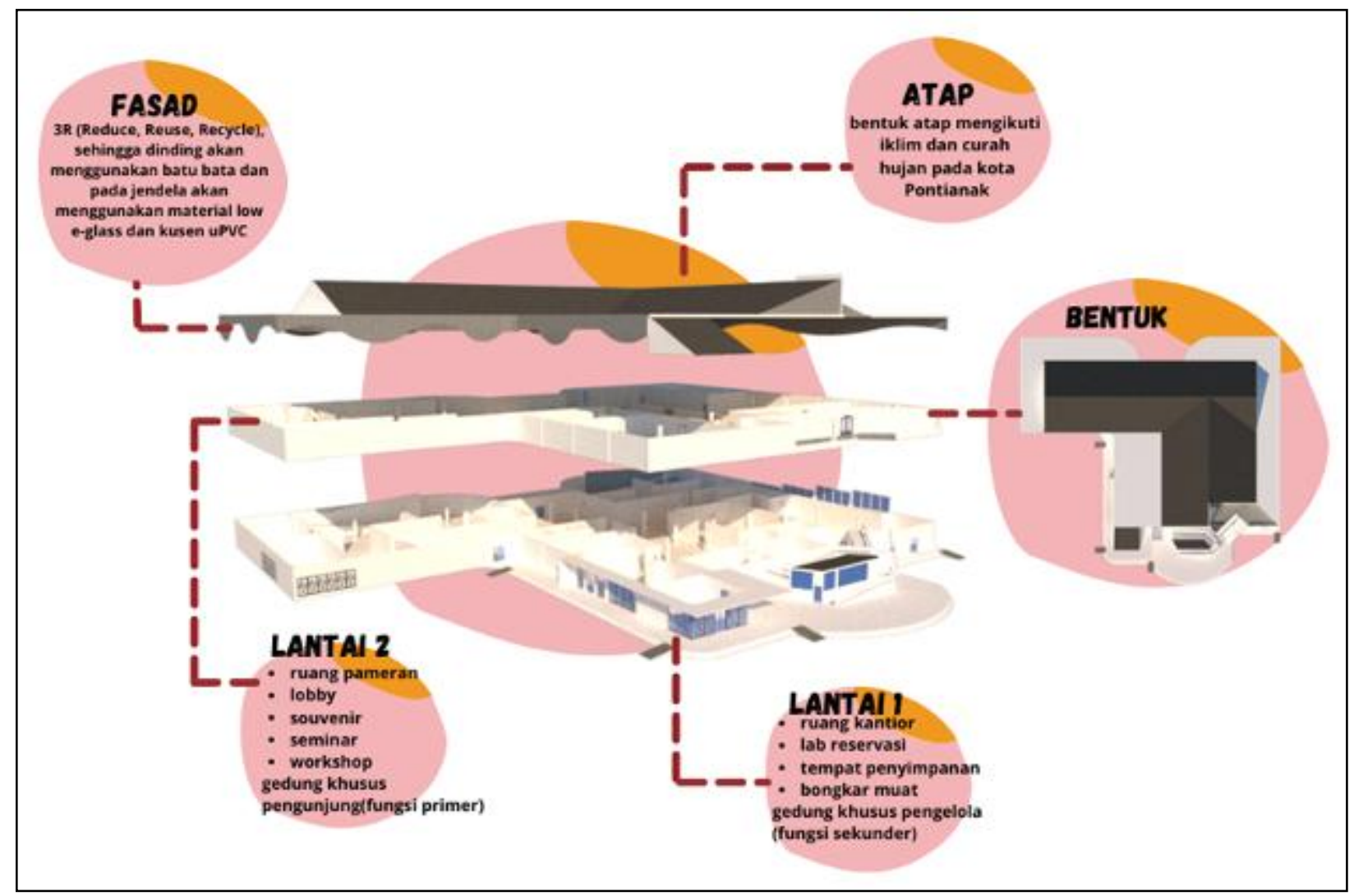

Gambar 4. Gubahan Bentuk

Sumber: Penulis, 2020

Sistem struktur pada perancangan museum terbagi menjadi dua yaitu, struktur atas dan bawah. Struktur atas menggunakan struktur rangka kaku (rigid frame). Sistem struktur ini terdiri dari kolom dan balok yang bekerja saling mengikat satu dengan yang lain. Kolom sebagai unsur vertikal bertugas menerima beban dan gaya, sedangkan balok sebagai unsur horizontal media pembagi beban dan gaya. Rangka atap menggunakan baja ringan truss juga sering disebut dengan galvalume atau zincalume. Baja ringan jenis $C$ truss untuk rangka atap, dan reng baja ringan. Jenis truss yang digunakan pada atap Museum Seni Rupa Modern di Pontianak jenis howe truss. Bentang atap yang diguankan memiliki panjang $24 \mathrm{~m}$ dengan tinggi $5 \mathrm{~m}$. Balok dan kolom menggunakan hollow berukuran 70/35 dan balok anak berukuran 55/30 dengan pertimbangan kuat tekan beton bertulang relatif lebih tinggi dari bahan lain konstruksi, memiliki ketahanan yang tinggi terhadap api dan air. Dinding menggunakan batako, plasteran, dan lapisan tresemme supaya dinding tahan air/tidak lembab. Plat lantai menggunakan material keramik, plasteran, karpet, dan vinyl. Struktur bawah menggunakan konstruksi cakar ayam berukuran 1,5 $\mathrm{m}^{2}$. 


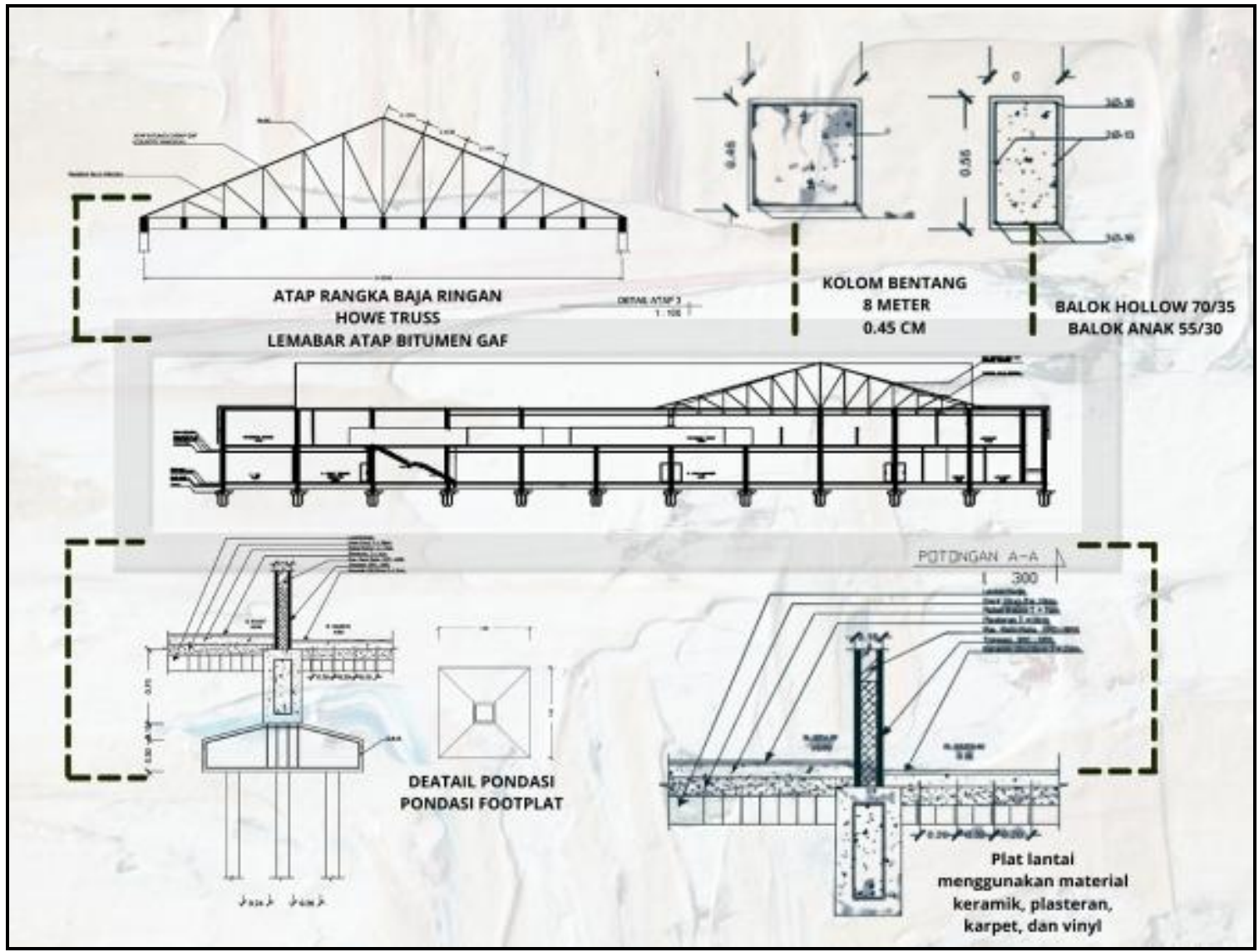

Gambar 5. Konsep Struktur

Sumber: Penulis, 2020

Konsep utilitas Museum Seni Rupa Modern di Pontianak mencakup sistem jaringan air, sistem jaringan listrik, sistem jaringan tata udara, sistem keamanan bangunan dan sistem persampahan. Kebutuhan air pada gedung museum memiliki total 7.750 L x 3 hari pemakaian dengan jumlah total 23.250 L dari hasil perhitungan menggunakan tangki TSH 25000. Air bersih pada bangunan disuplai menggunakan sistem up pipe dan down pipe. Air yang diperlukan dipompa dan dialirkan ke tangki bawah (resevoir), kemudian untuk mengalirkan air ke lantai-lantai atas pada bangunan bertingkat, air dipompa ke atas dengan bantuan tangki tekan kemudian disaring dengan hydro water solution for modern living. Sistem air kotor menggunakan sistem sewer septik tank, sistem ini dapat menampung 400 orang (pengelola dan pengunjung) menggunakan septik tank ukuran $28 \mathrm{~m}^{3}$ dengan uraian $(2,5 \mathrm{x}$ $6 \times 2,1)$.

Sistem mekanikal menggunakan aliran listrik PLN sebagai aliran utama dan panel surya untuk cadangan listrik. Bangunan ini berkonsep zero energy building, dimana sejumlah panel sel surya akan dilekatkan pada lapisan luar bangunan untuk menghasilkan energi listrik yang dibutuhkan bangunan (Karyono, 2010). Apabila terjadi kesalahan teknis pada perangkat listrik menggunakan generator sebagai alternatif listrik bangunan dengan $682,6 \mathrm{~kW}$ atau setara dengan $853,25 \mathrm{kVa}$ memerlukan generator dengan jenis (PR Power PR880P-SAE) dengan kapasitas $880 \mathrm{kVa}$ atau 704 kW. Sistem komunikasi bangunan menggunakan VPN (Virtual Privat Network) sangat aman mengakses pada jangkauan tertentu traffic tidak dapat disadap dengan mudah dan tidak memudahkan pihak lain menyusup. 


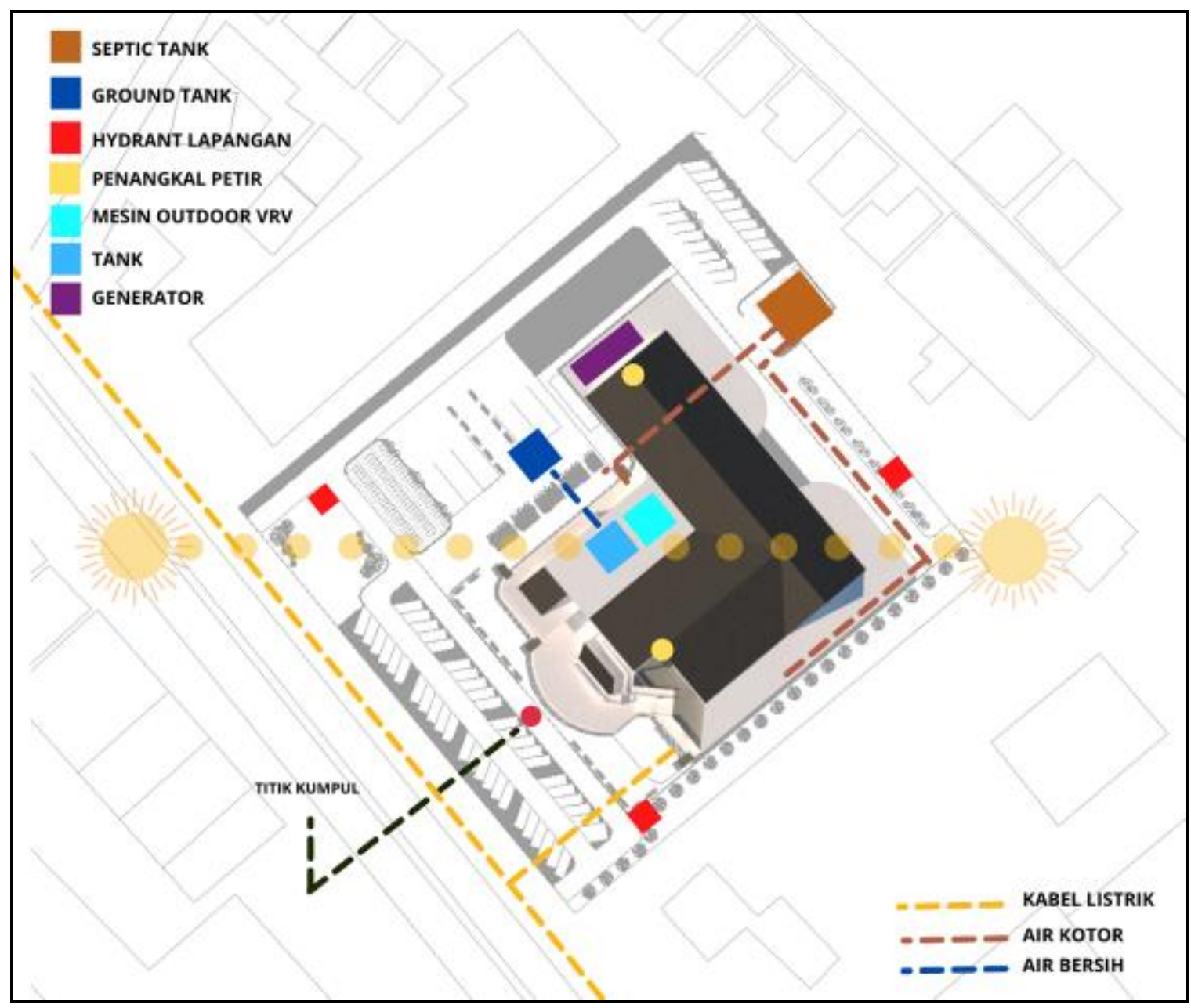

Gambar 6. Konsep Utilistas

Sumber: Penulis, 2020

Sistem keamanan menggunakan CCTV, penangkal petir dan proteksi kebakaran. Sistem CCTV yang digunakan ialah Sistem CCTV onfire 16 channel yang disalurkan oleh DVR menggunakan kontrol router dan dikontrol melalui smartphone. Sistem kebakaran menggunakan fire alarm sistem (konvensional) untuk gedung-gedung dengan blok simple dan mempunyai smart detektor (detekti panas dan deteksi gas). Sistem V6, yang cocok digunakan pada gedung terdapat 4 titik untuk area seluas 6 hektar atau setara dengan $60.000 \mathrm{~m}^{2}$, sistemnya mudah dalam perawatan dan sistem efisien dan hemat energi. Bangunan ini cukup menggunakan 2 titk yang mencakup luas $15.000 \mathrm{~m}^{2}$.

Perkiraan jumlah sampah untuk kawasan fungsi khusus, pengelola dan komersil yaitu 4,5 kg $/ \mathrm{m}^{2}$ (Juwana, 2005). Pembagian sampah tersebut meliputi, sampah kertas, kaca, organik dan nonorganik. Sampah-sampah akan dibedakan dengan tempat sampah berwarna sesuai dengan kegunaannya masing-masing.

Berdasarkan Direktorat Permuseuman Kementrian Pendidikan dan Kebudayaan tahun 1999, konsep fisika bangunan pada gedung Museum Seni Rupa Modern di Pontianak meliputi kenyamanan dengan sistem alami dan buatan yaitu pada pencahayaan, penghawaan, material fasad dan akustika gedung. Museum yang menyimpan koleksi utama harus mempunyai kelembaban $50 \%$ dengan suhu $21^{\circ} \mathrm{C}-26^{\circ} \mathrm{C}$. Intensitas cahaya yang disarankan sebesar 50 lux dengan meminimalisir radiasi ultra violet. 


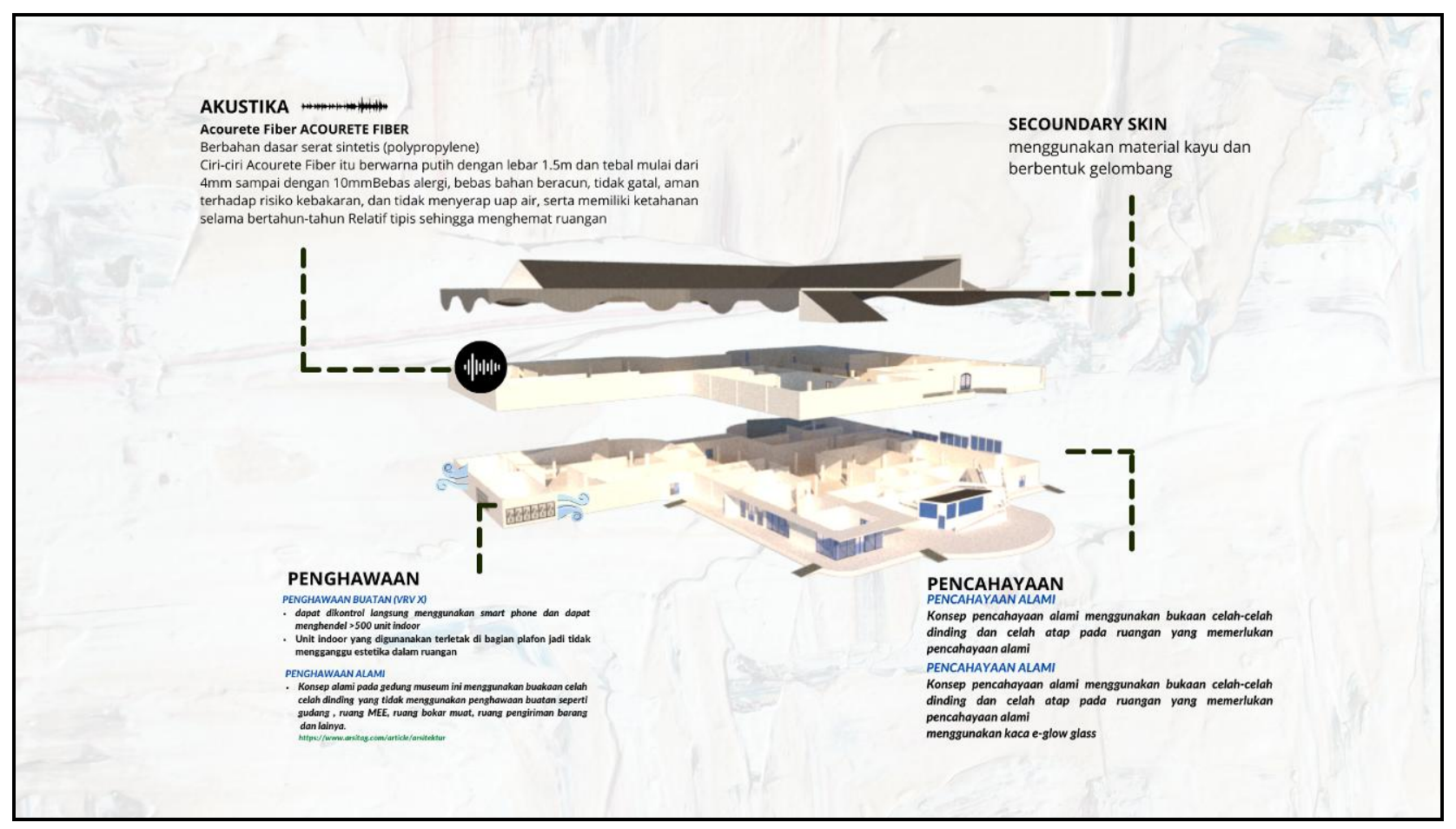

Gambar 7. Konsep Fisika Bangunan

Sumber: Penulis, 2020

\section{Hasil Perancangan}

Berdasarkan hasil analisis dan konsep keseluruhan, perancangan diperoleh hasil gambar pra perancangan Museum Seni Rupa Modern di Pontianak meliputi lantai satu dan lantai dua. Persyaratan ruang pada bangunan berdasarkan pernyataan Direktorat Permuseuman Kementrian Pendidikan dan Kebudayaan tahun 1999, dikelompokkan dan dipisahkan sesuai fungsi, aktivitas, keterangan, keramaian, dan keamanan. Pintu masuk (main entrance) utama diperuntukkan bagi pengunjung. Pintu masuk khusus (servis utama) untuk bagian pelayanan, perkantoran, rumah jaga serta ruang-ruang pada bangunan khusus.

Lantai satu dikhususkan untuk pengelola agar tidak mengganggu kegiatan masing-masing pengunjung dan pengelola. Lantai satu terdapat ruangan lobi pengelola, ruang penyimpanan, ruang penerimaan, ruang staf kurator, ruang kepala museum, ruang lab restorasi, ruang pameran temporer, ruang rapat, ruang tamu, kafetaria, ruang mekanikal elektrikal, ruang cctv dan keamanan. Ruang pameran temporer diletakan pada lantai ini supaya pengunjung atau pengelola mudah mengakses. Ruang pameran temporer dikhususkan untuk pameran dalam waktu yang singkat. Pada ruang pameran temporer ini tersedia lavatory dan gudang perlengkapan. Akses ruang pameran temporer berhubungan langsung dengan teras utama atau drop off utama yang memudahkan keluar masuknya pengunjung. Akses pengelola menggunakan pintu antara ruang pameran temporer dan ruang staf museum, supaya memudahkan pengelola mempersiapkan proses penyewaan. Ruangan berikutnya pada lantai dua ini meliputi ruang penyimpanan dan laboraturium restorasi.

Bedasarkan Undang-Undang Nomor 195 tahun 2015, penyimpanan koleksi harus dilakukan dengan memperhatikan pelindungan penyelamatan, pengamanan, dan pemeliharaan koleksi. Koleksi disimpan di ruang penyimpanan dan ruang pamer. Ruang penyimpanan dan perawatan jadi ruangan utama museum. Ruang penyimpanan berhubungan erat dengan ruang laboratorium. Ruangan penyimpanan dan laboratorium restorasi terbagi menjadi empat ruangan. Empat ruangan dikhususkan untuk ruang penyimpanan dan ruang laboratorium restorasi khusus untuk masingmasing jenis seni rupa modern di letakkan dengan ruangan terpisah. 


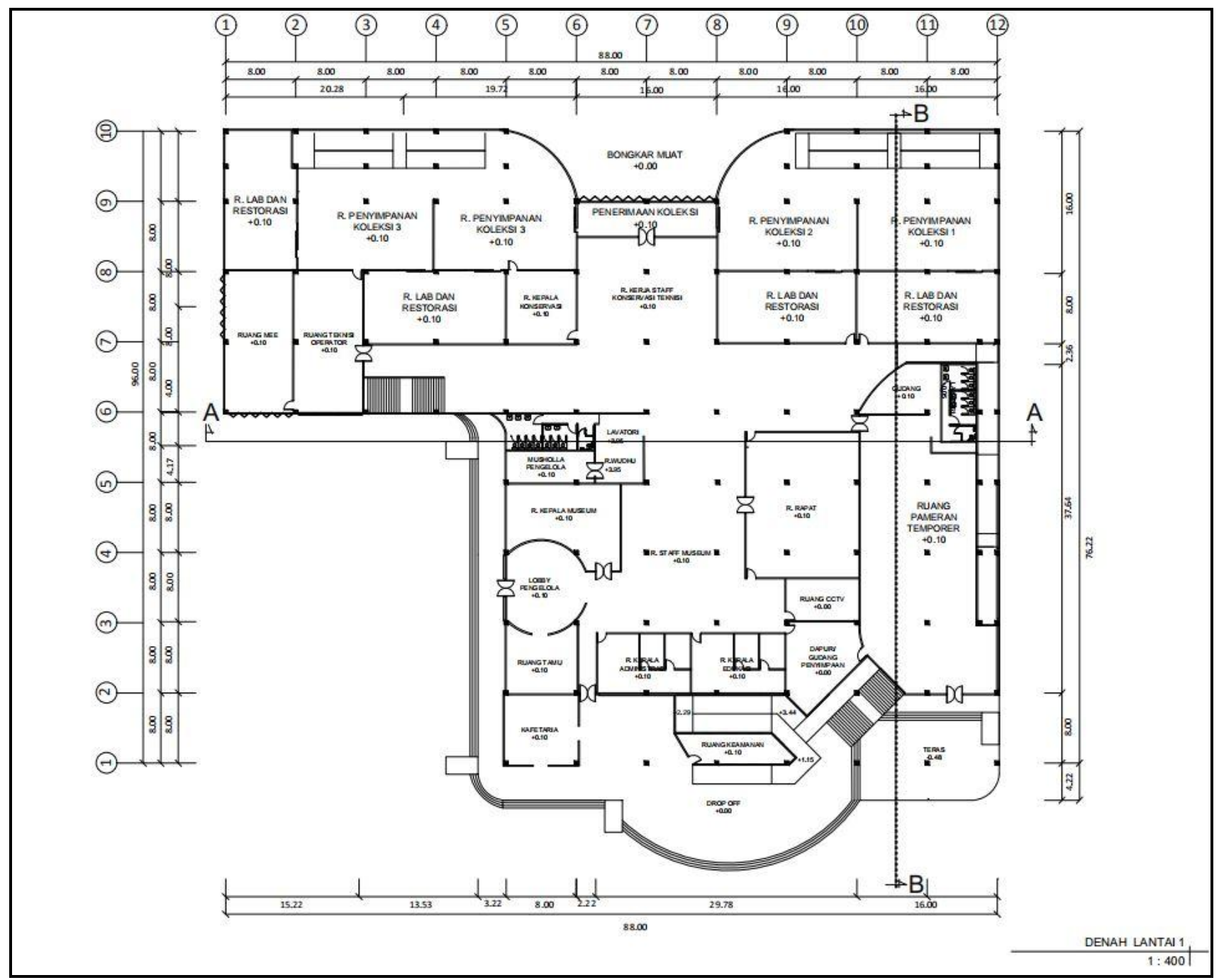

Gambar 8. Denah Lantai 1 pada Museum Seni Rupa Modern di Pontianak

Sumber: Penulis, 2020

Museum terdiri dari 2 lantai, lantai satu untuk pengelola dan lantai dua untuk pengunjung. Lantai satu dikhususkan untuk pengunjung dan tempat pameran tetap. Akses ke lantai dua menggunakan tangga dan ramp untuk mengakses ruang lobby utama pengunjung dan ruang pameran tetap. Saat masuk ke lobby pengunjung bertautan langsung dengan ruang CCTV dan pameran tetap, pameran tetap bertautan dengan ruangan seminar, musholla pengunjung, lavatory, ruang workshop dan pameran khusus.

Berdasarkan pernyataan Direktorat Museum Departemen Kebudayaandan Pariwisata tahun 2008, Penataan koleksi di ruang pameran museum, harus memiliki sistematika atau alur cerita koleksi. Sistematika atau alur cerita koleksi sangat diperlukan dalam penyajian di ruang pameran. Alur sirkulasi pada pameran tetap dimulai dari pintu lobi pengunjung dan berakhir dengan pintu keluar pada teras. Alur sirkulasi untuk penyajian koleksi dimulai dengan waktu terbentuknya seni rupa modern hingga koleksi terbaru agar mengenal sejarah, masa, dan jenis koleksi yang akan dipamerkan. 


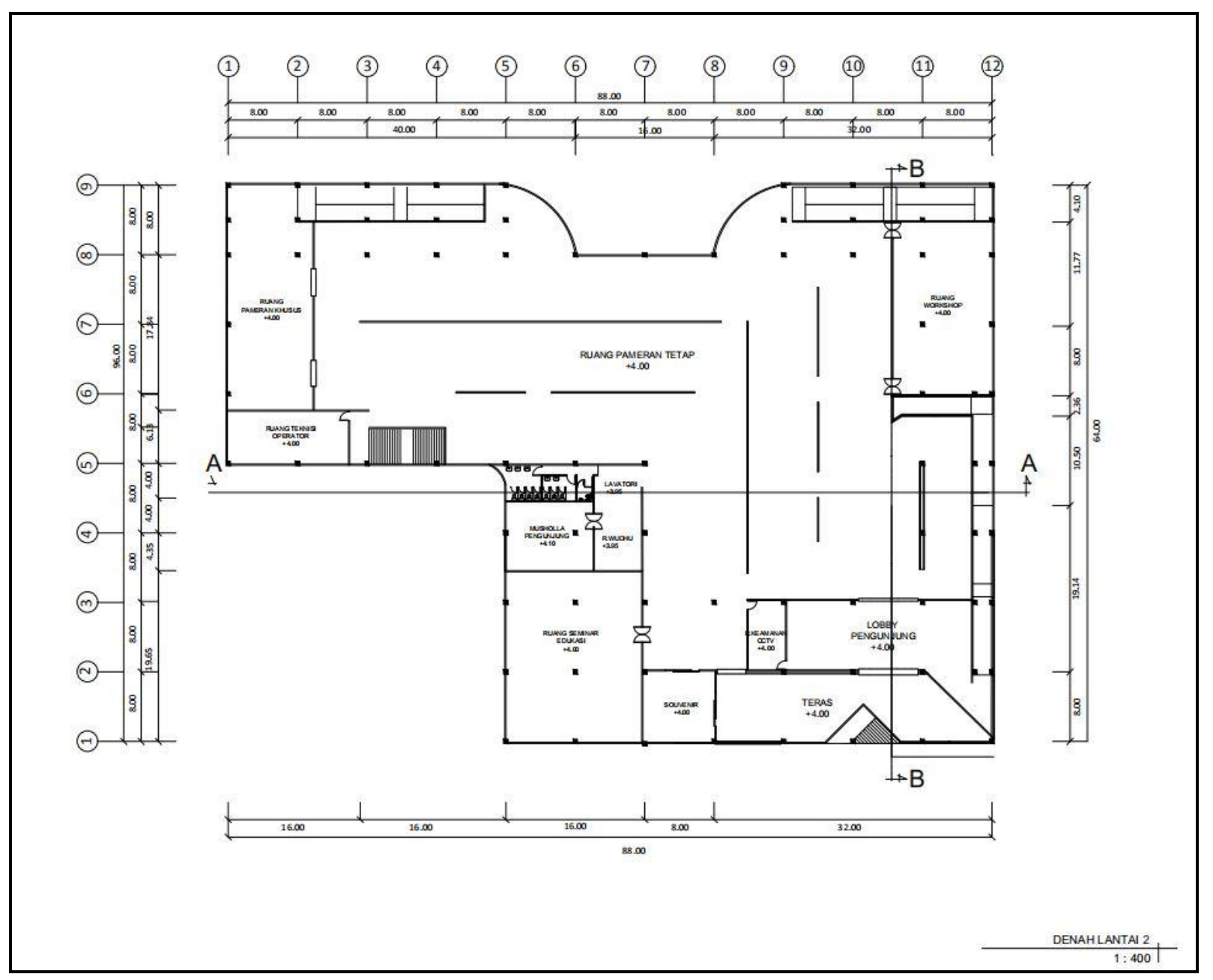

Gambar 9. Denah Lantai 2 Museum Seni Rupa Modern di Pontianak Sumber: Penulis, 2020

Terdapat empat bagian bangunan meliputi, bagian depan, bagian belakang, bagian kanan, dan bagian kiri. Bagian depan bangunan diawali dengan teras sebagai akses utama dan drop off. Bagian depan menunjukan pintu utama lobby pengunjung, pintu masuk pameran temporer, ruang keamanan, dan kafetaria. Tampak belakang akan terlihat pintu untuk menerima koleksi museum dan tempat bongkar muat serta dapat melihat jelas bentuk secondary skin seperti bentuk gelombang. Bagian kanan terdapat ramp yang akan terlihat pada jendela-jendela kaca, agar banyak masuknya cahaya dari arah timur. Bagian kiri menjadi jalur entrance utama bagi pengelola dan teknisi servis, agar tidak mengganggu jalur masuk utama pengunjung.
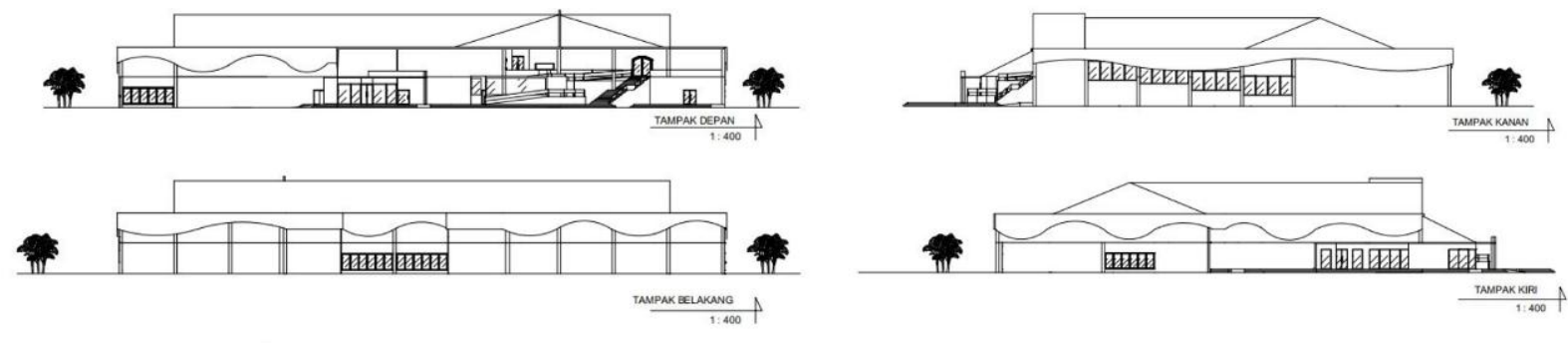

Gambar 10. Tampak pada Museum Seni Rupa Modern di Pontianak

Sumber: Penulis, 2020 
Lantai satu memiliki tinggi $4 \mathrm{~m}$ dengan pembagian 3,3 m untuk dasar lantai hingga plafond dan $70 \mathrm{~cm}$ untuk bagian plafond. Struktur atas pada bangunan Museum Seni Rupa Modern di Pontianak ini rangka baja ringan howe truss dengan bentang $24 \mathrm{~m}^{2}$ dan kemiringan $30^{\circ}$ yang berbentuk segitiga. Sturuktur balok menggukan balok hollow dan kolom berbahan dasar beton bertulang. Secondary skin menggunakan fasad berbahan 3R (reduce, reuse, recycle).

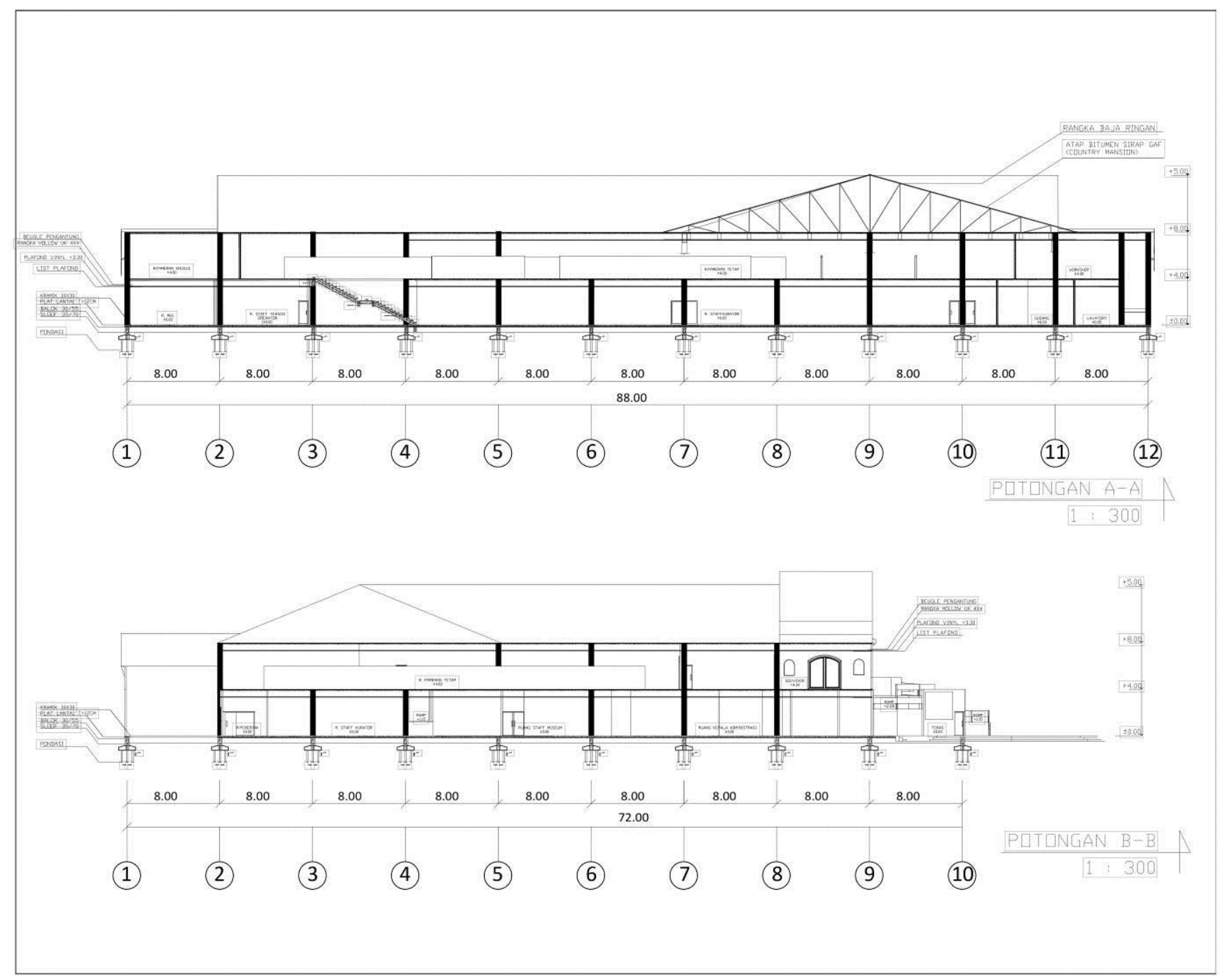

Gambar 11. Potongan pada Museum Seni Rupa Modern di Pontianak

Sumber: Penulis, 2020

Museum Seni Rupa Modern di Pontianak merupakan bangunan kebudayaan dan kesenian dengan pendekatan arsitektur hijau. Tampilan suasana eksterior campuran antara natural dan modern, dengan warna monokrom untuk meminimalisir cahaya matahari yang masuk pada gedung. Bentuk atap mengikuti kebutuhan atap pada iklim Kota Pontianak dengan rangka atap howe truss dan lembaran atap bitumen sirap GAF jenis country mansion. Suasana eksterior bagian depan yang mengarah langsung pada Jalan Jenderal Ahmad Yani, dan sebagai tempat drop off dan enterance utama. Suasana ekterior kedua diambil dari view mata burung agar terlihat suasana site plan dan bangunannya. Suasana sekitar gedung museum terdapat pohon rindang yang ditanami pada area pakir dan disekitar halaman museum, tidak terdapat pembatas pagar pada area museum tetapi pada area ini ditanami pohon rindang mengitari museum seni rupa modern. 


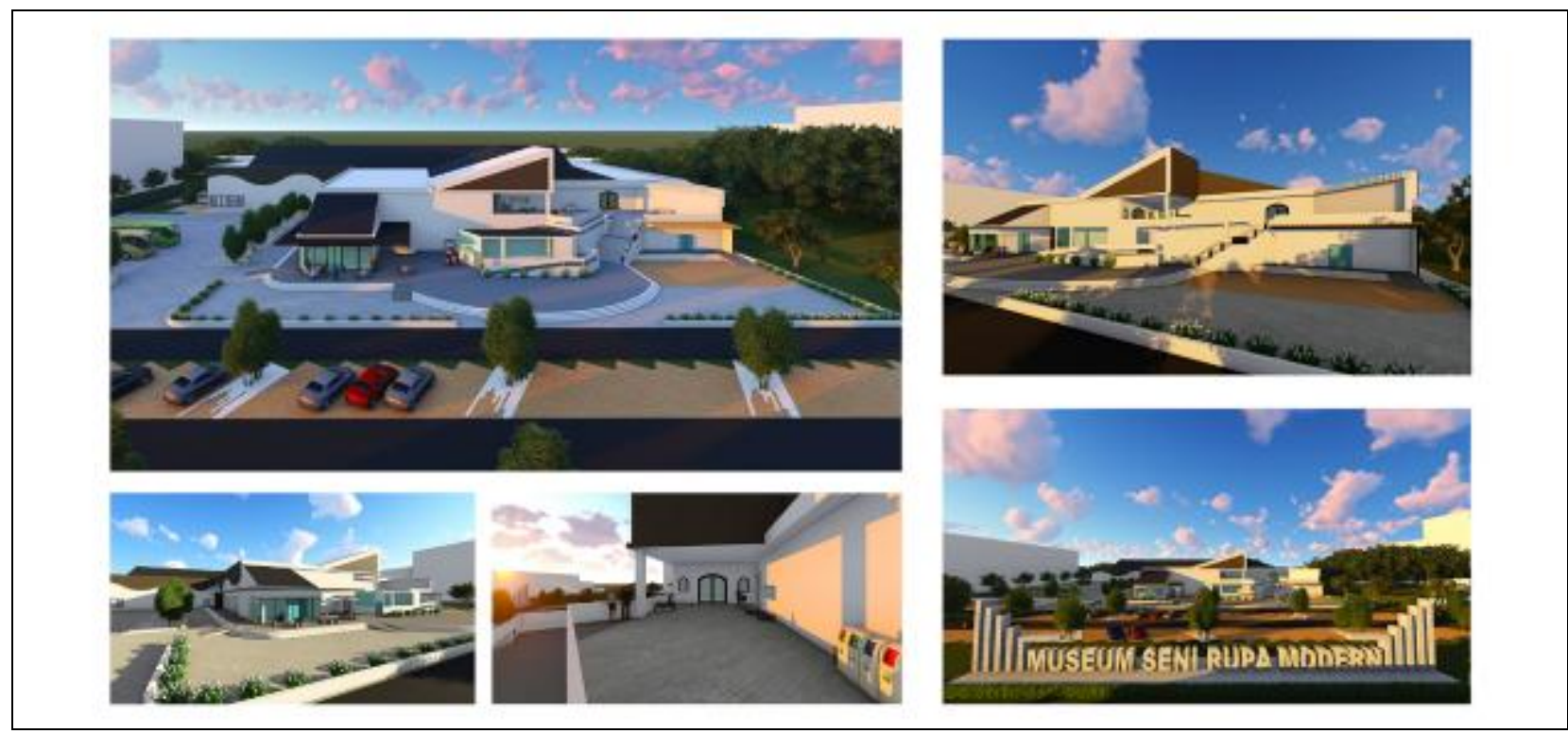

Gambar 12. Susana Eksterior pada Museum Seni Rupa Modern di Pontianak Sumber: Penulis, 2020

Suasana interior utama terdapat lobby pengunjung, dibuat dengan nyaman dengan plafond dan lantai menggunakan material vinyl dan dinding berwarna monokrom supaya terkesan modern dengan pencahayaan langsung menuju objek furniture. Fasilitas pada lobby meliputi sofa tunggu, vending machine, ruang informasi, mesin informasi, mesin tiket, komputer dan tempat penitipan barang. Warna dinding mengikuti warna dinding luar yang berwarna hitam putih dan warna natural pada lantai serta plafond agar modern dan natural mengikuti konsep utama pada perancangan museum seni supa modern. Material yang digunakan tidak mencemari lingkungan karena menggunakan material yang tidak mengganggu pengguna seperti penggunaan cat yang berbau (Karyono, 2014). Warna furniture disesuaikan dengan warna hitam, putih dan abu-abu yang mendominasi pada interior ruangan lobby pengunjung. Ruang pameran tetap yang senada dengan material lobby dan pencahanyaan spot ke karya yang di pamerkan.

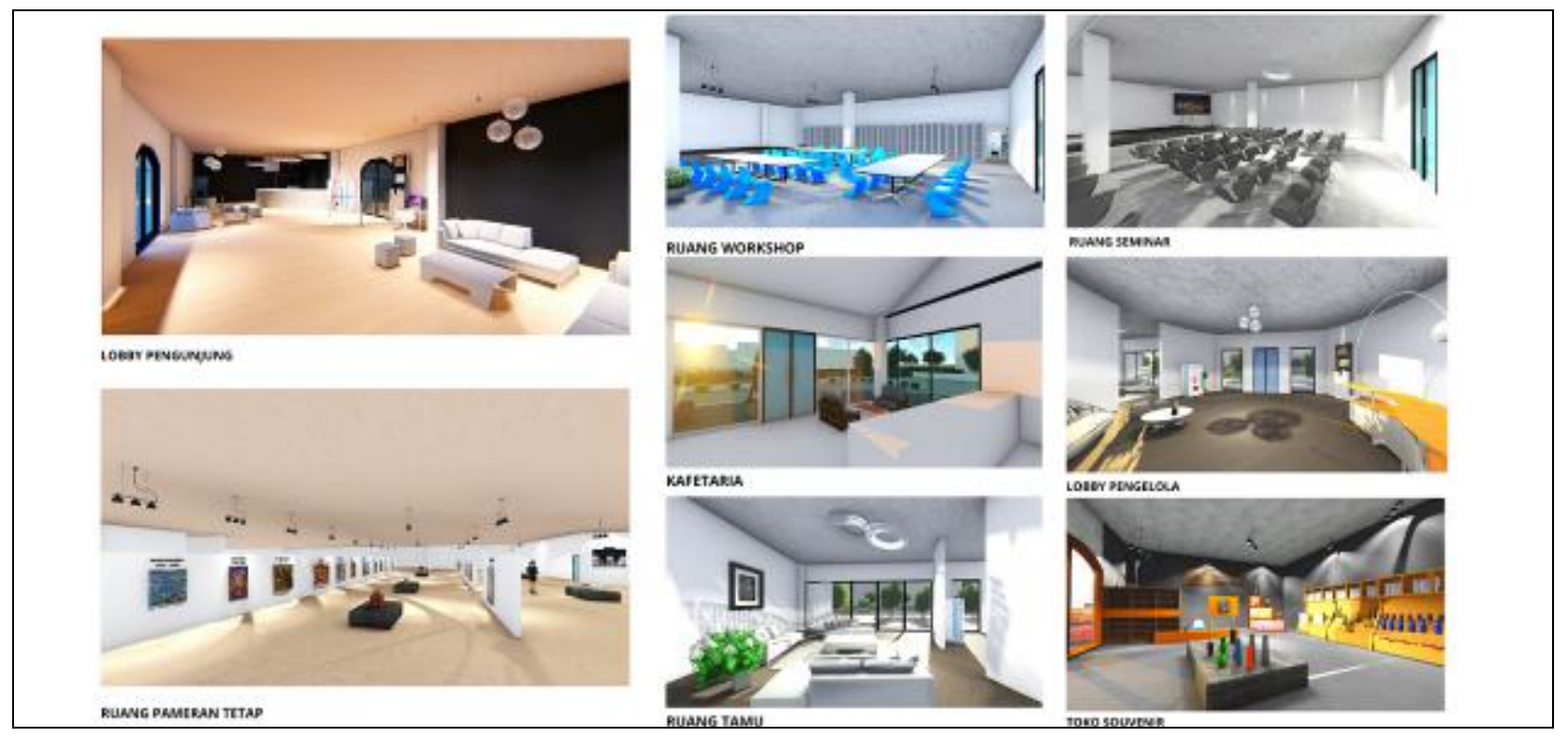

Gambar 13. Suasana Interior pada Museum Seni Rupa Modern di Pontianak

Sumber: Penulis, 2020 


\section{Kesimpulan}

Museum Seni Rupa Modern di Pontianak menjadi wadah untuk menyimpan, merawat, mengamankan dan memanfaatkan koleksi seni rupa modern, mengenalkan seni rupa modern dan sejarahnya kepada masyarakat Pontianak, kegiatan seni dan edukasi. Pendekatan arsitektur hijau berperan sebagai peminimalisir berbagai pengaruh membahayakan pada kesehatan manusia dan lingkungan. Dengan adanya wadah museum seni rupa modern ini akan menjadi wadah kegiatan wisata sambil belajar di lingkungan yang minim bahaya bagi masyarakat Pontianak dan sekitarnya.

\section{Ucapan Terima Kasih}

Puji syukur kepada Tuhan Yang Maha Esa, kepada kedua orang tua, kepada dosen-dosen pembimbing, kepada keluarga, kepada teman-teman dan pihak yang telah memberikan bantuan, bimbingan, dan pengertian selama proses pengerjaan Proyek Tugas Akhir ini. Penulis mengucapkan banyak terima kasih.

\section{Daftar Acuan}

Atkins, R. (1990). ArtSpeak: A Guide to Contemporary Ideas, Movements, and Buzzwords. New York, United States: Abbeville Press Publishers

Direktorat Museum. (1999). Kecil Tetapi Indah: Pedoman Pendirian Museum. Jakarta, Indonesia: Departemen Pendidikan dan Kebudayaan

Direktorat Museum. (2007). Pengelolaan Koleksi Museum. Jakarta, Indonesia: Departemen Kebudayaan dan Pariwisata

Direktorat Museum. (2008). Pedoman Museum Indonesia. Jakarta, Indonesia: Departemen Kebudayaandan Pariwisata

Direktorat Museum. (2009). Ayo Kita Mengenal Museum. Jakarta, Indonesia: Departemen Kebudayaan dan Pariwisata

Juwana, J. S. (2005). Sistem Bangunan Tinggi. Jakarta, Indonesia: Erlangga

Karyono, T. H. (2010). Green Arsitektur. Jakarta, Indonesia: PT Rajagrafindo Persada

Karyono, T. H. (2014). Pengantar Pemahaman Arsitektur Hijau di Indonesia. Jakarta, Indonesia: PT Radjagrafindo perkasa

Neufert, E. (2002). Data Arsitek Jilid 2. Jakarta, Indonesia: Penerbit Erlangga

Sachari, A. (2001). Estetika. Bandung, Indonesia: Institut Teknologi Bandung

Sekretariat Negara Republik Indonesia. (1995). Undang-Undang No. 19 Tahun 1995 Tentang Museum. Jakarta, Indonesia: Sekretariat Negara Republik Indonesia

Sekretariat Negara Republik Indonesia. (2015). Undang-Undang No. 66 Tahun 2015 Tentang Museum. Jakarta, Indonesia: Sekretariat Negara Republik Indonesia

Sekretariat Negara Republik Indonesia. (2015). Undang-Undang No. 195 Tahun 2015 Tentang Museum. Jakarta, Indonesia: Sekretariat Negara Republik Indonesia

Sumardjo, J. (2000). Filsafat Seni. Bandung, Indonesia: Institut Teknologi Bandung

Susilo, T. D. (1993). Kecil Tetapi Indah: Pedoman Pendirian Museum. Jakarta, Indonesia: Departemen Pendidikan dan Kebudayaan Direktorat Jenderal

Sutaarga, M. A. (1989). Pedoman Penyelenggaraan dan Pengelolaan. Jakarta, Indonesia: Proyek Pembinaan Permuseuman Jakarta 